\title{
Glottic Cancer pT4b TNM Finding v7
}

National Cancer Institute

\section{Source}

National Cancer Institute. Glottic Cancer pT 4b TNM Finding v7. NCI Thesaurus. Code C89069.

Glottic cancer with very advanced local disease. Tumor invades prevertebral space, encases carotid artery, or invades mediastinal structures. (from AJCC 7th Ed.) 